\title{
Correction to: Diet approach before and after bariatric surgery
}

\author{
Silvia Bettini ${ }^{1} \cdot$ Anna Belligoli $^{1} \cdot$ Roberto Fabris $^{1} \cdot$ Luca Busetto $^{1,2}$ \\ Published online: 17 August 2020 \\ (C) Springer Science+Business Media, LLC, part of Springer Nature 2020
}

\section{Correction to: Reviews in Endocrine and Metabolic Disorders. https://doi.org/10.1007/s11154-020-09571-8}

The original version of this article unfortunately, has the incorrect title reported in the published paper. The title of the Journal - Reviews in endocrine and metabolic disorders was captured and not the original title of the manuscript which is 'Diet approach before and after bariatric surgery'.

Thus, this erratum is presented to fix the error.

The original article has been corrected.

Publisher's note Springer Nature remains neutral with regard to jurisdictional claims in published maps and institutional affiliations.

The online version of the original article can be found at https://oi.org/ 10.1007/s11154-020-09571-8

Luca Busetto

luca.busetto@unipd.it

1 Center for the Study and the Integrated Management of Obesity, Padova University Hospital, Padova, Italy

2 Clinica Medica 3, Azienda Ospedaliera di Padova, Via Giustiniani 2, 35128 Padova, Italy 